\title{
Productive Aging and Gender Differences on Time Use Pattern among Retirees
}

\section{Aziera Adleen Adnan, Sharifah Azizah Haron}

To Link this Article: http://dx.doi.org/10.6007/IJARBSS/v11-i2/9189

DOI:10.6007/IJARBSS/v11-i2/9189

Received: 18 December 2020, Revised: 13 January 2021, Accepted: 30 January 2021

Published Online: 16 February 2021

In-Text Citation: (Adnan \& Haron, 2021)

To Cite this Article: Adnan, A. A., \& Haron, S. A. (2021). Productive Aging and Gender Differences on Time Use Pattern among Retirees. International Journal of Academic Research in Business and Social Sciences, 11(2), 892-903.

\section{Copyright: (c) 2021 The Author(s)}

Published by Human Resource Management Academic Research Society (www.hrmars.com)

This article is published under the Creative Commons Attribution (CC BY 4.0) license. Anyone may reproduce, distribute, translate and create derivative works of this article (for both commercial and non-commercial purposes), subject to full attribution to the original publication and authors. The full terms of this license may be seen at: http://creativecommons.org/licences/by/4.0/legalcode

Vol. 11, No. 2, 2021, Pg. 892 - 903

Full Terms \& Conditions of access and use can be found at http://hrmars.com/index.php/pages/detail/publication-ethics 


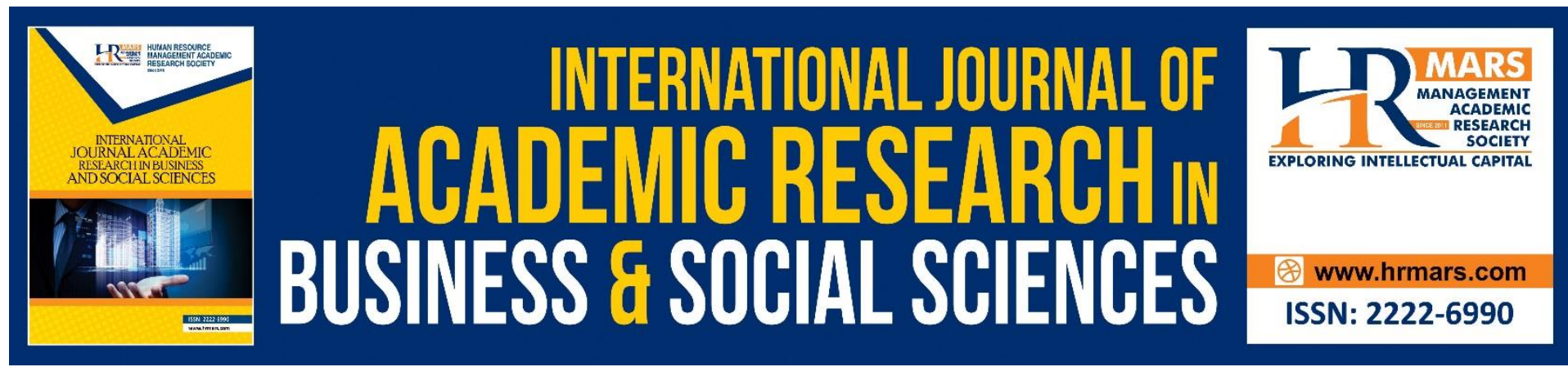

\title{
Productive Aging and Gender Differences on Time Use Pattern among Retirees
}

\author{
Aziera Adleen Adnan, Sharifah Azizah Haron \\ Department of Resource Management and Consumer Studies, Faculty of Human Ecology, \\ Universiti Putra Malaysia, Serdang, Selangor, Malaysian Research Institute on Aging \\ (MyAgeing), Universiti Putra Malaysia, Serdang, Selangor, Malaysia
}

\begin{abstract}
Malaysia will become an "aged nation" by 2040 when elderly population aged 60 years and above. By 2040, elderly population was projected to risen from 3.3 million in 2020, to a staggering over 6 million. Population aging carry with it many social, economic and health issues and implication to various layers of stakeholders in a nation - e.g., the older persons themselves, the family, the community and businesses. Often, studies focus on the negative aspect of aging, forgetting the opportunity that aging population can present, thus, not optimally utilizing older person as resources. Shift to a positive perspective towards older person will put them in the mainstream and ensure inclusivity in the development process i.e. incorporating older person into society. This study attempted to shed light on the concept of productive aging - a concept consisted of paid work and non-paid work which symbolize one's productivity in both labour force and productive activities unaccounted for in the National Accounting such as household management and caregiving. It is also important to assess the gender differences since, productive activities not accounted for in the National Accounting are mostly performed by women. Therefore, the specific objective of the study is to measure difference in time use pattern for these productive activities in an attempt to reveal gender role stereotyping of women even in old age. Data will be analysed using IBM Statistical Package for Social Sciences (SPSS) version 25. Independent sample t-test was utilized to assess the gender differences. In addition, acknowledging the gendered patterns of productive aging can assist in the development of effective interventions for improving the life quality for both elderly men and women.
\end{abstract}

Keywords: Older Person, Productive Aging, Time Use Pattern, Productive Activities, Gender.

\section{Introduction}

One of the most crucial demographic phenomena around the globe denotes the growth of the aging population with older individuals of age 60 years old and above. As indicated by the World Health Organization, the number of aging population is expected to rise from 524 million in the year 2010 to about 1.5 billion in the year 2050 (Abdullah \& Wolbring, 2013). Notwithstanding, Malaysia is also not excluded from aging. Currently, the aging population in Malaysia has increased rapidly and it is estimated that 15 percent of the Malaysian population will become aged by the year 2035. In general, the elderly population was expected to 
increase from 3.3 million in 2020 to more than 6 million in 2040 (Mansor, Awang, \& Rashid, 2019).

On a par with other Asia-Pacific countries, the percentage of the aging population in Malaysia increases steadily since the nation also has better healthcare systems in addition to low mortality rate, longer life expectancy, and fertility decline (Ong \& Phillips, 2007). Consequently, the aging population tends to live longer and experience significant life changes as they grow older (Wan-Ibrahim \& Zainab, 2014). In line with the increasing percentage of the aging population, existing and extensive information regarding this particular population segment is, thus, necessary. Besides, developed capitalist nations have also made relevant endeavors to reduce the negative consequences of aging (Hinterlong, Morrow-Howell, \& Rozario, 2007).

Population aging carry with it many social, economic and health issues and implication to various layers of stakeholders in a nation - e.g. the older persons themselves, the family, the community and businesses (Maestas, Mullen, \& Powell, 2016). As studies usually concentrate on the negative aspects of aging and overlook the opportunities presented by the aging population; hence, this population is unlikely to be optimally utilised as resources. Kim (2019) asserted that older individuals are utilizable assets that may sustain labour force productivity and reduce the fiscal burden. Correspondingly, this implies the beneficial importance of the elderly population and its integration into society.

Productive aging emphasizes the constructive elements of aging and how individuals can contribute essentially not only to their lives but also to communities, societies, organizations, and networks (Hinterlong \& Sherraden, 2001). This study seeks to elucidate the productive aging concept, which entails paid work and non-paid work that denote productivity in labour force and the productive activities excluded in National Accounting such as caregiving and household management. As such, gender differences should be highlighted since such productive activities are primarily performed by women (Maestas, Mullen, \& Powell, 2016).

There is a common stigma or misbelief surrounding women to be more engaged in "women's work" such as preparing food, handling clothing materials, or caring for children. According to Dong \& An (2015), women presumably spend most of their time performing housework as opposed to men. As such, this study specifically aims to examine the difference in the time-use pattern of these productive activities in order to identify gender role stereotyping of women, even those of old age.

\section{Literature Review}

Productive activities of the elderly and productive aging

Productive aging has been described and highlighted in prior literature as a result of productive activities. The assumption surrounding the productive aging concept is that older individuals tend to continuously perform productive activities that are social- and economicoriented (Sahlen et al., 2012). According to (Budlender, 2010), productive activities refer to the social and economic production of services and goods, which allows for skill development and values towards further production. On a narrower term from the economic viewpoint, productive activities performed by older individuals are the ones that bring value to the market. However, broadly speaking, these activities are associated with involvements by the older individuals such as participating in the labour market and other non-economic activities such as voluntary work or supporting their friends and other people (Gauthier \& Smeeding, 2010). 
As defined by Butler (1985), productive activities are referred to as the involvement of individuals in producing goods and services through activities such as volunteering, housework, and giving protection to children. As such, older individuals are assumed to engage in productive activities such as in the production of services and goods or any activities that contribute to such productions. Briefly, older individuals contribute to society by demonstrating their values through social and economic productive activities besides utilizing resources, hence the productive aging concept (Rowe \& Kahn, 1996). In short, this includes all activities that may improve their abilities that, in turn, enable them to perform any tasks more independently

According to Balcombe \& Sinclair (2001), productive activities employed by developing nations comprise four categories: market activities such as working; non-market activities with economic values such as caring for young children or elderly family members; formal social and civic activities such as voluntary work in social welfare agencies and schools; and informal social assistance such as helping other people. In the context of India, a productive aging study divides productive activities into four categories: work such as social involvement and contributing to household financials or grandparenting; household financial matters such as clearing bills and handling economic issues; grandparenting such as caring for grandchildren; and finally, social engagement (Visaria \& Dommaraju, 2019).

Studies on productive activities remain discussed to date. For instance, a study in the Korean context classifies productive activities into three categories (Kim \& Min, 2019). that include older individuals' activities for getting a profession, helping family members and relatives, and participating in the local community. The categorisation in this study coincides with another study that divides productive activities into formal and informal voluntary work, working, and caregiving. For instance, training and education to gain practical work skills, voluntary work, and daily activities for family members and the community (Maestas, Mullen \& Powell, 2016).

Briefly, previous studies have defined the productive activities of older individuals based on several types of categories. To date, the literature on productive aging remains rather sporadic, with the latest trend stemmed towards interpreting and defining productive activities in a wider context to uncover certain classification types that describe the productive activities of older individuals (Luo, Pan \& Zhang, 2019). While most scholars have used two classification types to define productive activities in this context, the classification can still be expanded to three or four domains as discussed in this paper.

In this study, productive activities will be categorized into four behavioral domains per the criteria listed in the 2014 Time-Use Survey, which coincides with the study conducted in South Korea by Kim (2019). In this context, the first domain includes labor-related activities such as paid labor, unpaid labor, and unpaid family labor. Next, the second domain entails household management activities such as paying household bills, preparing food, and caring for children. Subsequently, the third domain includes care/support activities involving family care such as caring for partners or grandchildren and relatives, participating in social events for the community's benefits, supporting other people, and doing voluntary work. Finally, the fourth domain entails self-development practices such as acquiring training and education to empower abilities and skills, socializing with other people and relations in many groups, engaging in religious activities, and participating actively in leisure activities (Kim, 2019). 
Research on time-use

The reality of productive aging will be captured in this study through a detailed investigation of the daily time-use among older individuals. The application of a time-use survey for examining the frequency and length of human activities is widespread around the world. In general, this type of survey functions by requiring the respondents to report all of their activities in 24 hours via daily, weekly, or the entire week. The daily time for all activities must equal 24 hours or 1440 minutes (Hamermesh, Frazis \& Stewart, 2005). As such, a sole emphasis on a respondent's daily life allows for the recognition of specific procedures and standards of the time-use survey as a successful application (Skirbekk, 2008).

Since the time-use survey is widely applied across the globe for examining the length and frequency of human activities (Paúl, Ribeiro \& Teixeira, 2012), this type of survey can also be effectively used to measure and comprehend productive aging that involves older individuals in terms of the structure of their daily life. It also enlightens understanding and provides more knowledge of the time-use pattern of the aging population (Kim, 2019). Further, the time-use survey is evidently more beneficial to assess unpaid care work, work, and non-work interdependence compared to the conventional household survey (Esquivel et al., 2008).

The National Bureau of Statistics (NBS) of China commenced its first national representative time-use survey in 2008 by releasing a volume of statistics overview of how the Chinese spend their time performing various and diverse activities according to their gender, age, education, and jobs. Later, the published information and data were used to examine time-use patterns in China in comparison to other countries around the world (Chang, Dong \& MacPhail, 2011). Although scarce, Dong \& An (2015) strengthened the claims based on the data acquired from the 2008 China Time-Use Survey, which was applied to examine gender patterns concerning the time spent for paid jobs, unpaid care work, and other non-work activities and to estimate the currency worth of unpaid care work.

Apart from that, a research by the Ministry of Women, Family, and Community Development in Malaysia had conducted a small modular time-use survey throughout the agricultural season together with 14 time-use surveys and statistics in Asia as well the Pacific FAO including other agencies under the United Nations. Unluckily, information was scarcely available and this might be due to the small scale of the time-use survey application (Hirway, 2010).

Since the time-use survey is available and appropriate for measuring productive activities involving older individuals, this study will, therefore, use this type of survey to uncover extensive information related to how the older individuals spend their time daily or every week. In general, the time-use survey technique is a detailed combination of extensiveness and precision that other social surveys may not achieve (Samantroy \& Khurana, 2015).

\section{Data and Methods}

Secondary data from the "Comparative Data Collection Methods for Time-Use Study among Older Persons", which took place in 2018 and was funded by the Ministry of Education through the Fundamental Research Grant Scheme (FRGS) were employed in this study. The aging population consists of UPM retirees from 2011-2016. Since they resided around Klang Valley, the samples from the secondary data were collected from several housing areas in the Klang Valley region. A total list of 769 retirees outlined from 'Persatuan Pesara UPM' was 
obtained through the Registrar's Office. However, upon screening, there were only 576 retirees who resided in Klang Valley; hence, they were chosen as the initial sample pool.

The researcher employed a purposive sampling technique as the researcher would determine what must be learnt and identify those who can give necessary information based on their expertise or experience (Tongco, 2007). In this study, information on the list of UPM retirees was requested and obtained from UPM Registrar's Office (Service Leave and Retirement Section). Upon screening the list, the researcher contacted the respondents by phone to obtain their permission to take part in the study and further scheduled an appointment with each of them for the purpose of data collection.

The sample selection is based on the respondents' willingness to participate in the study and a total of 211 respondents was selected upon excluding some potential respondents such as those who refused to take part, had relocated, or passed away. Based on Krejcie \& Morgan's (1970) table for determining the sample size of a given population, a total of 576 UPM retirees (upon screening) would require a sample size of 226 to 234 individuals. However, since there were only 211 respondents from Klang Valley based on the secondary data, the small population of UPM retirees is, thus, not compatible with the above formula.

The respondents were required to respond to a three-day activity (one weekend and two weekdays) through recall and direct recording of activities. The data collection involves two stylised methods. The first one is the stylised method via interviews, by which a trained enumerator would visit the respondents on the first day to record and recall the activities performed by the respondents on the previous day through a face-to-face interview. This would be done to give early exposure to the respondents regarding the questions in the questionnaire. Briefly, the respondents would be interviewed by the enumerator, their background information as well as their activities on the previous day would be directly recorded. Next, the second method is the stylised method via self-report, by which the respondents themselves would conduct self-report of time-use on the second and third days.

This study employed questionnaires written in the Malay language as the instrument to collect the data, which was adapted from The United Nations guidebook (2005) for the data collection on time-use. The research instrument was based on the stylised method by which the researcher presents a list of activities and requires the respondents to report how much time was spent on each activity throughout the reference day (Council, 2000). Unlike the diary method that requires respondents to name the activities that they spend their time on, the purpose of the stylised method is to ease the activity notation among the elderly respondents. Further, the questionnaires comprise socio-demographic section and time-use sections that include three parts: one weekend and two weekdays.

To analyse the data, the Statistical Package for Social Sciences (SPSS) version 25 software would be used through the independent sample t-test to measure the hypotheses on gender differences. Productive activities will be captured through the time-use classification system based on the 2014 Time-Use Survey, which comprises four domains of labour-force activities, household management activities, care/support activities, and selfmanagement activities.

\section{Results}

Descriptive statistics

The demographic characteristics of the participants are provided in Table 1 . Out of 210 questionnaires distributed to respondents, 210 questionnaires were returned. That gives a 
response rate of $100 \%$. More than half of respondents were male $62.6 \%$ and the rest are female $37.4 \%$. As shown in the table, a total of 211 respondents participated in this research. The respondents age was in the range of 52-66 years old. The largest share of respondents consisted of elderly in the range of 61 to 63 years old (50.7\%) and the least of them were above 64 years old with (20.4\%).

Besides, most of the respondents are fully retired (85.8\%), the least are selfemployed/ running business (6.6\%) while others are still working as part time/ full time job (7.6\%). Most of the respondents are married (85.7\%) and 26 of them had no spouse $(12.4 \%)$ because of death. 2 persons are single (1.0\%) and were divorced (1.0\%) respectively. Apart from that, most of the respondents had a very good health status $(96.2 \%)$ as compared to those 8 persons who had a poor health status (3.8\%).

Table 1. Demographic characteristics

\begin{tabular}{|l|c|c|}
\hline \multicolumn{1}{|c|}{ Variables } & Frequency (n) & Percentage (\%) \\
\hline Gender & 132 & 62.6 \\
Male & 79 & 37.4 \\
Female & & \\
\hline Age (average age: 62 years old) & 61 & 28.9 \\
<60 years old & 107 & 50.7 \\
$61-63$ years old & 43 & 20.4 \\
$>$ 64 years old & & \\
\hline Employment status & 16 & 7.6 \\
Part time/ full time job & 14 & 6.6 \\
Self-employed/ Business & 181 & 85.8 \\
Fully retired & & 1.0 \\
\hline Marital status & 2 & 85.7 \\
Single & 180 & 1.0 \\
Married & 2 & 12.4 \\
Divorce & 26 & 96.2 \\
Death of spouse & & 3.8 \\
\hline Health status & 202 & \\
Good & 8 & \\
Poor & & \\
\hline
\end{tabular}

Time use pattern in productive activities

The classification of time use study can be classified into four domains which was previously stated in literature review. Thus, in this study, time use pattern in productive activities will be captured using the daily time use classification system utilized in the 2014 Time Use Survey which consists of four domains: 1) labour force activities, 2) household management activities, 3) care/support activity and 4) self-development activities.

Table 2 illustrates the result of an independent t-test. An independent-samples t-test was conducted to compare the gender differences in time use pattern for these productive activities. There is a significant difference in the household management activities for men $(M=8.3, S D=4.643)$ and women $(M=12.7, S D=3.963)$ conditions; $t=-7.265, p=0.000$. Furthermore, there is a significant difference in time use pattern for self-management activities with men $(M=8.1, S D=9.337)$ and women $(M=3.7, S D=6.759)$ conditions; $t=3.948$, $p=0.000$. 
On the other hand, there is no significant in the labour force activities for men $(M=10.5, S D=8.259)$ and women $(M=9.0, S D=5.098)$ conditions; $t=0.667, p=0.511$. Although the labour force activities are insignificant, the time use pattern for these activities is higher for men compared to women. Besides, there is no significant difference in the care/support activities between men and women. The result of $p$-value was more than $0.05, p=0.567$.

Table 2. Result of independent t-test in productive activities for men and women

\begin{tabular}{|l|c|c|c|c|c|c|}
\hline Variable Group & Gender & Mean & SD & $\mathbf{t}$ & MD & $\mathbf{p}$ \\
\hline Labour force & 1 & 10.5 & 8.259 & 0.667 & 1.461 & 0.511 \\
activities & 2 & 9.0 & 5.098 & & & \\
\hline Household & 1 & 8.3 & 4.643 & -7.265 & -4.434 & 0.000 \\
management & 2 & 12.7 & 3.963 & & & \\
activities & & & & & & \\
\hline Care or support & 1 & 6.3 & 5.862 & -0.575 & -0.607 & 0.567 \\
activities & 2 & 6.9 & 5.701 & & & \\
& & & & & & \\
\hline Self-management & 1 & 8.1 & 9.337 & 3.948 & 4.407 & 0.000 \\
activities & 2 & 3.7 & 6.759 & & & \\
\hline
\end{tabular}

1: Men; 2: Women; SD: Standard deviation; MD: Mean difference.

Care/ support activities have been separated into two groups which are activities of caregiving for family and activities of social engagement for community. Table 3 recorded the result of independent t-test in those two groups of care/support activities.

Activities of caregiving for family include five questions such as caring for children (e.g., babysit, bringing to clinic etc.), caring for grandchildren (e.g., babysit, keeping accompany, bringing to clinic etc.), caring for spouses/ adult family members (e.g. senior citizen, OKU), helping other family members and caring for pets (pet care). The result of $p$ value of caregiving for family was more than $0.05, p=0.341$ that indicates there is no significant difference between men and women. However, women tend to spend more hours in this activity which is in the average of 6.5 hours a day.

In addition, activities of social engagement for community include caring for adult (e.g., senior citizen, OKU) not family members, involve in community activities and society/ groups/ clubs ('gotong royong', meetings, 'marhaban'), involve in volunteering (volunteers), ceremony and event (e.g., wedding, open house), travelling related to community activity and sending help to other household and others care/ support activities. On the other hand, there is no significant difference in the activities of social engagement for community for men $(\mathrm{M}=3.6, \mathrm{SD}=2.667)$ and women $(\mathrm{M}=3.3, \mathrm{SD}=3.064)$ conditions; $\mathrm{t}=0.513, \mathrm{p}=0.611$.

Table 3. Result of independent t-test in care/support activities for men and women

\begin{tabular}{|l|c|c|c|c|c|c|}
\hline Variable Group & Gender & Mean & SD & t & MD & p \\
\hline Caregiving for family & 1 & 5.4 & 5.971 & -0.957 & -1.145 & 0.341 \\
& 2 & 6.5 & 5.832 & & & \\
\hline Social engagement & 1 & 3.6 & 2.667 & 0.513 & 0.385 & 0.611 \\
for community & 2 & 3.3 & 3.064 & & & \\
\hline
\end{tabular}

1: Men; 2: Women; SD: Standard deviation; MD: Mean difference. 
Furthermore, Table 4 portrays the result of independent t-test for self-management activities that have been divided into three groups. The groups are self-care activities, leisure and recreational activities and lastly, educational activities. Although the overall result of selfmanagement activities is significant, the result for each separated groups of self-management activities are insignificant. The mean difference for all three groups between men and women are slightly contrast.

The time use pattern for the first group which is self-care activities has no significant different for men $(M=14.2, S D=4.638)$ and women $(M=13.4, S D=4.476)$ conditions; $t=1.180$, $p=0.240$. Moreover, leisure and recreational activity along with educational activities have no significant different because the results of $p=0.308$ and $p=0.932$ respectively. Nonetheless, older persons do spend most of their time on doing leisure and recreational activities. The highest time spent for older persons on this self-care activities followed by leisure and recreational activities are around 13 to 17 hours on an average day.

Table 4. Result of independent t-test in self-management activities for men and women

\begin{tabular}{|l|c|c|c|c|c|c|}
\hline Variable Group & Gender & Mean & SD & t & MD & p \\
\hline Self-care activities & 1 & 14.2 & 4.638 & 1.180 & 0.764 & 0.240 \\
& 2 & 13.4 & 4.476 & & & \\
\hline Leisure and & 1 & 17.2 & 6.562 & 1.023 & 0.962 & 0.308 \\
recreational & 2 & 16.2 & 6.599 & & & \\
activities & & & & & & \\
\hline Educational activities & 1 & 5.1 & 3.385 & -0.086 & -0.047 & 0.932 \\
& 2 & 5.2 & 3.599 & & & \\
\hline
\end{tabular}

1: Men; 2: Women; SD: Standard deviation; MD: Mean difference.

\section{Discussion}

Based on the research results, women have higher labour value in household production than men. Evidently, women devoted 4.4 hours more time for housework duties as opposed to men and this coincides with the results reported by Gauthier \& Smeeding (2010) that women still spend most of their time performing housework than men. This study is also in line with Maestas, Mullen \& Powell (2016) who asserted that while women devote more time to unpaid work, men devote more time to paid work than women.

The results further revealed that men devote more time for self-management activities such as self-care activities, leisure and recreational activities, and educational activities with 4.4 hours more time as opposed to women. This is similar to a study by Dong \& An (2015) by which the time allocated for paid jobs among older men involves different activity types such as self-care and recreational activities. Recently, Galiana et al., (2016) in their time-use study stated that older adults are devoting more time to leisure activities involving the media and books with the decrease in time for paid work.

Nonetheless, an insignificant difference was observed in the time-use pattern of labour force activities and care/support activities between men and women. Similar to the results reported by Luo, Pan \& Zhang (2019), despite the insignificant difference, the result is significant for the activities they perform with the increase in their age. Besides, the rates of labour force participation among older individuals in many developed nations since the 1990s have been increasing through the 2000s (Ng \& Feldman, 2008). Thus, this study proves that the UPM's retirees are still working in the market even though they had retired from their previous job. 


\section{Conclusion}

Gender was employed in this study as the focal point to analyse and understand the data in detail. As reported in prior literature, time use patterns vary significantly by gender, particularly as unpaid work activities are concerned. However, it is not surprising to see an unequal time distribution for unpaid care work, especially involving women with a large share of duties for household management activities. This underlines the "double invisibility" of care work among women, which is typically conducted at home as simultaneous activities as well as excluded from the market-based measurements and in the National Accounting. Hence, society should value paid and unpaid work alike and distribute unpaid care work equally not only among men and women but also families, the market, and the state at large.

To improve research feasibility involving the aging population, several guidelines for the collection and presentation of data could be implemented. For example, the published data should be broken down into age and sex so far as gender is concerned. In general, productive aging relative to physical activities is likely to influence older individuals in keeping their quality of life and health. As evidenced in this study, it is therefore important that policies, especially social policies for promoting productive aging, include gender differences in the organisation of events or social programs including their implications for productive aging.

In sum, despite the view that the aging population tends to be inactive, the older individuals might still be able to produce for the household or care for their grandchildren. These activities, although may not be deemed "economic", are still essential for the family's survival. Besides, gender-disaggregated data are necessary for enlightening how older women and men live including what they do and what they require. As such, policymakers are able to make prompt decisions regarding the developmental effects of older individuals as well as the impact of the growth of the aging population on development.

\section{Acknowledgements}

This study was funded through "Fundamental Research Grant Scheme" (FRGS), Ministry of Education Malaysia under research program entitled "Comparative Data Collection Methods for Time Use Study Among Older Person" (Project No. (FRGS/1/2015/SS06/UPM/02/05).

\section{Corresponding Author}

Aziera Adleen Adnan. Department of Resource Management and Consumer Studies, Faculty of Human Ecology, Universiti Putra Malaysia, Serdang, Selangor.

Email: gs55543@student.upm.edu.my

\section{References}

Abdullah, B., \& Wolbring, G. (2013). Analysis of Newspaper Coverage of active aging through the lens of the 2002 World Health Organization active ageing report: a policy framework and the 2010 Toronto charter for physical activity: a global call for action. International Journal of Environmental Research and Public Health, 10(12), 6799-6819.

Balcombe, N. R., \& Sinclair, A. (2001). Ageing: definitions, mechanisms and the magnitude of the problem. Best Practice \& Research Clinical Gastroenterology, 15(6), 835-849.

Chang, H., Dong, X. Y., \& MacPhail, F. (2011). Labor migration and time use patterns of the left-behind children and elderly in rural China. World Development, 39(12), 21992210. 
Council, N. (2000). Inquiry and the national science education standards.

Budlender, D. (Ed.). (2010). Time use studies and unpaid care work. Routledge.

Butler, R. N. (1985). Productive aging: Enhancing vitality in later life. New York: Springer Publishing.

Dong, X. Y., \& An, X. (2015). Gender Patterns and Value of Unpaid Care Work: Findings From China's First Large-Scale Time Use Survey. Review of Income and Wealth, 61(3), 540560.

Esquivel, V., Budlender, D., Folbre, N., \& Hirway, I. (2008). Explorations: Time-use surveys in the south. Feminist Economics, 14(3), 107-152.

Galiana, L., Gutiérrez, M., Sancho, P., Francisco, E. H., \& Tomás, J. M. (2016). Sociodemographic variables and successful aging of the angolan elderly. Scientifica, 2016.

Gauthier, A. H., \& Smeeding, T. M. (2010). Historical trends in the patterns of time use of older adults. In Ageing in advanced industrial states (pp. 289-310). Springer, Dordrecht.

Hamermesh, D. S., Frazis, H., \& Stewart, J. (2005). Data watch: The American time use survey. Journal of Economic Perspectives, 19(1), 221-232.

Hinterlong, J. E., Morrow-Howell, N., \& Rozario, P. A. (2007). Productive engagement and late life physical and mental health: Findings from a nationally representative panel study. Research on Aging, 29(4), 348-370.

Hirway, I. (2010). Time-Use surveys in developing countries: An assessment. In Unpaid Work and the Economy (pp. 252-324). Palgrave Macmillan, London.

Kim, H. J., Min, J. Y., \& Min, K. B. (2019). Successful Aging and Mortality Risk: The Korean Longitudinal Study of Aging (2006-2014). Journal of the American Medical Directors Association, 20(8), 1013-1020.

Kim, J. H. (2019). Productive aging of Korean older people based on time use. Social Science \& Medicine, 229, 6-13.

Krejcie, R. V., \& Morgan, D. W. (1970). Determining sample size for research activities. Educational and psychological measurement, 30(3), 607-610.

Luo, Y., Pan, X., \& Zhang, Z. (2019). Productive activities and cognitive decline among older adults in China: Evidence from the China Health and Retirement Longitudinal Study. Social Science \& Medicine, 229, 96-105.

Maestas, N., Mullen, K. J., \& Powell, D. (2016). The effect of population aging on economic growth, the labor force and productivity (No. w22452). National Bureau of Economic Research.

Mansor, N., Awang, H., \& Rashid, N. F. A. (2019). Malaysia ageing and retirement survey. Encyclopedia of gerontology and population aging. Switzerland: Springer Nature Switzerland AG, 1-5.

Morrow-Howell, N., Hinterlong, J., \& Sherraden, M. (Eds.). (2001). Productive aging: Concepts and challenges. JHU Press.

Naciones Unidas. División de Estadística, Statistical Division Staff, \& United Nations. Statistical Division. (2005). Guide to Producing Statistics on Time Use: Measuring Paid and Unpaid Work (Vol. 93). United Nations Publications.

$\mathrm{Ng}$, T. W., \& Feldman, D. C. (2008). The relationship of age to ten dimensions of job performance. Journal of applied psychology, 93(2), 392.

Ong, F. S., \& Phillips, D. R. (2007). Older consumers in Malaysia. International Journal of Ageing and Later Life, 2(1), 85-117. 
Paúl, C., Ribeiro, O., \& Teixeira, L. (2012). Active ageing: an empirical approach to the WHO model. Current gerontology and geriatrics research, 2012. Rowe, J. W. \& Kahn, R. L. (1996). Successful aging. The Gerontologist, 37 (4), 433-440.

Sahlen, K. G., Löfgren, C., Brodin, H., Dahlgren, L., \& Lindholm, L. (2012). Measuring the value of older people's production: a diary study. BMC health services research, 12(1), 4.

Samantroy, E., \& Khurana, S. (2015). Capturing Unpaid Work: Labour Statistics and Time Use Surveys. Gender Issues and Challenges in Twenty-First Century.

Skirbekk, V. (2008). Age and productivity capacity: Descriptions, causes and policy options. Ageing horizons, 8, 4-12.

Tongco, M. D. C. (2007). Purposive sampling as a tool for informant selection. Ethnobotany Research and applications, 5, 147-158.

Visaria, A., \& Dommaraju, P. (2019). Productive aging in India. Social Science \& Medicine, 229, 14-21.

Ahmad, W. I., \& Ismail, Z. (2014). Some demographic aspects of population aging in Malaysia. World Applied Sciences Journal, 30(7), 891-894. 